\title{
High dietary fat intake lowers serum equol concentration and promotes prostate carcinogenesis in a transgenic mouse prostate model
}

\author{
Yufei Liư ${ }^{\dagger}$, Xiaobo $\mathrm{Wu}^{\dagger}$ and Haowen Jiang ${ }^{*}$ (D)
}

\begin{abstract}
Background: Consumption of diet high in soy products is suggested to contribute to lower prostate cancer incidence in Asian men. But little has been known about the influences of dietary patterns on gut microbiota and microbiota-mediated isoflavone metabolism. Here, we determined the influences of western pattern diet on prostate carcinogenesis, gut microbiota and microbiota-mediated equol metabolism using a transgenic adenocarcinoma of mouse prostate (TRAMP) model.
\end{abstract}

Methods: We mimicked the western pattern diet using a high fat diet (HFD). TRAMP mice were fed with either control diet (CD) or HFD. At the age of 24 weeks, mice were orally administered daidzein over a 4-day period, and then sacrificed. The serum daidzein and equol were analyzed by ultra high performance liquid chromatography. Fecal microbiome was analyzed with fecal $16 \mathrm{~S}$ rRNA pyrosequencing, and prostate was dissected and performed with histopathology.

Results: HFD could promote prostate carcinogenesis in TRAMP mice $(p=0.045)$. The daidzein showed no significant differences between CD and HFD groups, while equol was significantly decreased in HFD group $(p=0.019)$. Fecal microbiotas differed between the two groups, 21 microbial phylotypes were increased and 11 phylotypes were decreased in abundance in HFD group, including decreased abundance of equol-producing bacterium Adlercreutzia ( 0 . $08 \%$ vs. $0.27 \%)$.

Conclusions: HFD may promote prostate carcinogenesis through adversely affecting equol-producing bacterium. Further functional validations are required to ascertain the mechanism of those HFD-responsive bacteria in carcinogenesis.

Keywords: Prostate cancer, High fat diet, Gut microbiota, Daidzein, Equol

\section{Introduction}

Prostate cancer $(\mathrm{PCa})$ is the most frequently diagnosed cancer in men worldwide, with an estimated 1.1 million cases and 307,500 deaths globally in 2012 [1]. There is a noticeable discrepancy in PCa incidence rates between Asian and Western countries. In addition to ethnic and genetic factors, consumption of diet high in soy products is suggested to contribute to lower PCa incidence in Asian men [2, 3].

Isoflavones, including daidzein and genistein, are commonly contained in soy products. Numerous studies have

\footnotetext{
* Correspondence: urology_jhw@126.com

${ }^{\dagger}$ Yufei Liu and Xiaobo Wu contributed equally to this work.

Department of Urology, Huashan Hospital, Fudan University, No. 12 Middle Wulumuqi Road, Shanghai 200040, China
}

described isoflavones' protective role against $\mathrm{PCa}$ due to their estrogenic properties $[4,5]$. For example, daidzein could induce cell-cycle arrest of prostate cancer cell in G0/G1 phase via impacting the gene expression of cyclins and cyclin-dependent kinases (CDKs) [6]. Equol is secondary metabolite of daidzein produced by the intestinal microbiotas with stronger anti-carcinogenic activity than daidzein. According to a 14,203 Japanese men based study conducted by Norie Kurahashi et al., plasma equol was significantly associated with a decreased risk of $\mathrm{PCa}$, especially localized cancers [7]. Equol normally exists as a diastereoisomer but intestinal bacteria synthesize exclusively the S-(-)equol enantiomer, not R-(+)equol. The S-(-)equol has selective affinity for the estrogen

(c) The Author(s). 2019 Open Access This article is distributed under the terms of the Creative Commons Attribution 4.0 International License (http://creativecommons.org/licenses/by/4.0/), which permits unrestricted use, distribution, and 
receptor- $\beta[8]$. What's more, not all men and women are equol-producer, $30-50 \%$ of adults lack those equol-producing bacteria to metabolite daidzein to S-equol.

Bidirectional interactions exist between diet and gut microbiota, diet influences the profile of microbiota, and microbiota inversely affects the metabolism of dietary elements. Available studies are limited to the observation of the discrepancy of PCa incidence between Asian and Western countries, possibly because of soy consumption, but few have investigated the influences of dietary patterns on gut microbiota and microbiota-mediated equol metabolism. In the present study, we mimicked the western pattern diet using high fat diet (HFD), and observed the effects of HFD on S-equol metabolism and prostate carcinogenesis using a transgenic adenocarcinoma of mouse prostate (TRAMP) model. We also examined the variation of gut microbiota under HFD consumption that may be associated with equol production.

\section{Methods and materials Materials}

Daidzein (D-2946) was purchased from LC laboratories (Woburn, USA); S-(-)equol (SML2147) was purchased from Sigma-Aldrich (Germany); Equol-d4 (E593002) was purchased from Toronto Research Chemicals (TRC, Canada).

\section{Animals}

Animals were handled with IACUC approval by the Fudan University (Grant No. 2017 1674 A641). Transgenic TRAMP females (purchased from Jackson Laboratory, Bar Harbor, USA) were bred with nontransgenic C57BL/6 males (Jackson Laboratory). At age of 2 weeks, the transgenic males were selected by genotyping as previously reported. TRAMP mice were randomly categorized into two groups after weaning (postnatal day 20) and singly housed and fed either control diet (CD, $n=6)$ (16\% of calories from fat, SLAC Inc., http://www.slaccas.com; Shanghai, China) or HFD $(n=6)$ ( $40 \%$ of calories from fat, SLAC Inc.) (Table 1$)$. At age of 24 weeks, daidzein was administered orally to the HFD and CD groups for 4 days. Daidzein was dissolved in DMSO. Each mouse was given $3 \mathrm{mg}$ of daidzein dissolved in $0.2 \mathrm{ml}$ of DMSO for the first 3 days, and $6 \mathrm{mg}$ of daidzein dissolved in $0.2 \mathrm{ml}$ of DMSO on the fourth day [9].

Table 1 Composition of HFD and control diet

\begin{tabular}{llllll}
\hline Composition & HFD & & & \multicolumn{2}{c}{ Control diet } \\
\cline { 2 - 3 } \cline { 6 - 6 } & gm\% & gm\% & & gm\% & Kcal\% \\
\hline Protein & 17 & 15 & & 15 & 15 \\
Carbohydrate & 52 & 45 & 69 & 69 \\
Fat & 20 & 40 & 7 & 16 \\
Total & & 100 & & 100 \\
Kcal/gm & 4.6 & & 4.0 & \\
\hline
\end{tabular}

\section{Samples}

Fecal samples were collected one day before the daidzein administration, and immediately stored at $-80^{\circ} \mathrm{C}$ until gut microbiota analysis. Sixteen hours after daidzein administration on the fourth day, the mice were sacrificed. The blood was harvested from the portal vein, and the serum was collected and stored at $-80^{\circ} \mathrm{C}$ until UHPLC-MS/MS analysis. The prostate was removed and fixed for histopathological analysis based on a modified grading system for prostatic lesions in TRAMP mice.

\section{Serum UHPLC-PRM-MS/MS analysis}

A $60 \mu \mathrm{L}$ aliquot of each individual sample was added to $180 \mu \mathrm{L}$ methanol (containing $50 \mathrm{ng} / \mathrm{mL}$ internal standard) in an Eppendorf tube. The samples were vortex mixed for $30 \mathrm{~s}$, incubated at $-20^{\circ} \mathrm{C}$ for one hour and then centrifuged at $12000 \mathrm{rpm} 4{ }^{\circ} \mathrm{C}$ for $15 \mathrm{~min}$. A $200 \mu \mathrm{L}$ aliquot of supernatant was transferred to a new tube and dried under gentle nitrogen flow. The residual was reconstituted with $50 \mu \mathrm{L}$ of $50 \%$ methanol, centrifuged at $12000 \mathrm{rpm} 4{ }^{\circ} \mathrm{C}$ for $15 \mathrm{~min}$. A $40 \mu \mathrm{L}$ aliquot of supernatant was transferred to an auto-sampler vial for UHPLC-MS/MS analysis.

Stock solutions were prepared by dissolving daidzein or S-equol standard substance to a concentration of $10 \mu \mathrm{g} /$ $\mathrm{mL}$. Aliquots of each stock solution were mixed to form the standard solution at $1 \mu \mathrm{g} / \mathrm{mL}$. The calibration standard solutions were then prepared by stepwise dilution of mixed standard solution. Equol-d4 was used as the internal standard (IS) at a concentration of $100 \mathrm{ng} / \mathrm{mL}$.

The UHPLC separation was carried out using an Agilent 1290 Infinity series UHPLC System (Agilent) coupled with an ACQUITY UPLC BEH C18 column $(100 \times 2.1 \mathrm{~mm}$, $1.7 \mu \mathrm{m}$, Waters, Ireland). The mobile phase consisted of A = water containing $10 \mathrm{mmol} / \mathrm{L}$ ammonium acetate $/ \mathrm{ammo}-$ nia, and $\mathrm{B}=$ methanol. The column temperature was set at $40{ }^{\circ} \mathrm{C}$, the auto-sampler temperature was set at $4{ }^{\circ} \mathrm{C}$, and the injection volume was $2 \mu \mathrm{L}$. Analysis was carried out using a Q Exactive Focus mass spectrometer (Thermo Fisher Scientific) under parallel reaction monitoring (PRM) model. The ion source parameters were: spray voltage $=+$ $3500 /-3100 \mathrm{~V}$, sheath gas (N2) flow rate $=40$, aux gas $(\mathrm{N} 2)$ flow rate $=15$, sweep gas $(\mathrm{N} 2)$ flow rate $=0$, aux gas $(\mathrm{N} 2)$ temperature $=350^{\circ} \mathrm{C}$, capillary temperature $=320^{\circ} \mathrm{C}$.

\section{Fecal 16S rRNA gene amplicon pyrosequencing and sequence analysis}

Fecal DNA was extracted using the DNeasy PowerSoil Kit (QIAGEN, Inc., Netherlands). Regions V3-V4 of the 16S rRNA gene were amplified using the forward primer 5'-ACTCCTACGGGAGGCAGCA-3', and the reverse primer 5'-GGACTACHVGGGTWTCTAAT-3'. The PCR program was set: $98^{\circ} \mathrm{C} 10 \mathrm{~min}, 25$ cycles of $98^{\circ} \mathrm{C} 15 \mathrm{~s}, 55^{\circ}$ C $30 \mathrm{~s}, 72{ }^{\circ} \mathrm{C} 30 \mathrm{~s}$, and $72{ }^{\circ} \mathrm{C} 5 \mathrm{~min}$. After agarose gel electrophoresis, the PCR amplicons were purified using the 
Agencourt AMPure Kit (Beckman Coulter, Milan, Italy) and quantified using the PicoGreen dsDNA Assay Kit (Invitrogen, Carlsbad, CA, USA). An equimolar amplicon pool was obtained, and paired-end $2 \times 300 \mathrm{bp}$ sequencing was performed using the Illlumina MiSeq platform with MiSeq Reagent Kit v3 (Shanghai Personal Biotechnology Co., Ltd., Shanghai, China).

The sequencing data were analyzed using QIIME V1.8.0 package [10]. Sequences were excluded from analysis if they (a) were $<150$ nucleotides in length, (b) had average Phred scores of $<20$, (c) contained ambiguous bases or mononucleotide repeats of $>8 \mathrm{bp}$. Paired-end reads were aligned using FLASH [11], and operational taxonomic units (OTUs) delineation was conducted with UCLUST at a 97\% cutoff [12]. A representative sequence of each OTU was selected and subjected to BLAST to assign taxonomic classification using the Greengenes $16 \mathrm{~S}$ rRNA gene database. Alpha and beta diversity were performed using QIIME. LEfSe analysis was performed on website http://huttenhower.sph.harvard.edu/galaxy to identify differentially abundant phylotypes with both statistical significance and biological relevance [13].

\section{Statistical analysis}

The Student's t-test, nonparametric test and Spearman's rank correlation coefficient were used for statistical analysis with SPSS 20.0 software. $P<0.05$ was regarded as statistical significant.

\section{Results}

\section{Overall situation of TRAMP mice}

No mice died until sacrifice at the 24th week. The body weights of HFD and CD mice were $26.86 \pm 0.87$ and 23.48 $\pm 2.99 \mathrm{~g}$, respectively $(P=0.024)$. The prostate weights of
HFD and CD mice were $0.545 \pm 1.139$ and $0.076 \pm 0.017 \mathrm{~g}$, respectively $(P=0.336)$.

\section{Effects of HFD on prostate carcinogenesis}

The $\mathrm{CD}$ group exhibited one case of moderate- and five cases of high-grade prostate intraepithelial neoplasia (PIN), while the HFD group exhibited three cases of high-grade PIN and three cases of prostate cancer $(p=0.045)$ (Fig. 1).

\section{Serum isoflavones}

The serum concentrations of daidzein and S-equol were measured. There is no significant differences in daidzein concentration between HFD and CD groups (418.21 \pm $153.26 \mathrm{ng} / \mathrm{ml}$ vs. $387.16 \pm 103.47 \mathrm{ng} / \mathrm{ml}, p=0.513$ ) (Fig. $2 \mathrm{a}$ ). However, the $\mathrm{S}$-equol concentration was significantly decreased in HFD group $(2.76 \pm 1.17 \mathrm{ng} / \mathrm{ml}$ vs. $4.32 \pm 1.60$ $\mathrm{ng} / \mathrm{ml}, p=0.019$ ) (Fig. 2b).

\section{Differences in gut microbiome between HFD and CD groups}

We profiled the gut microbiome of two groups of mice to determine whether HFD may influence the microbial populations. Alpha-diversity can indicate the richness of microbial communities. The average Shannon diversity index [14] for HFD and CD groups were $8.85 \pm 0.23$ and $8.98 \pm$ $0.47(p=0.55)$, respectively, no statistical significances were observed between the two groups. We further determined the average relative abundance of bacteria within each group (Fig. 3a, b). At the phylum level, the HFD group had increased abundance of Bacteroidetes (66.53\% vs. $57.10 \%)$, TM-7 (1.33\% vs. $0.45 \%)$, Tenericutes $(0.13 \%$ vs. $0.10 \%)$; and decreased abundance of Firmicutes (28.37\% vs. $36.29 \%)$, Proteobacteria (2.47\% vs. $3.97 \%)$, Actinobacteria (1.06\% vs. $1.68 \%)$, Deferribacteres (0.04\% vs.0.30\%), and Cyanobacteria
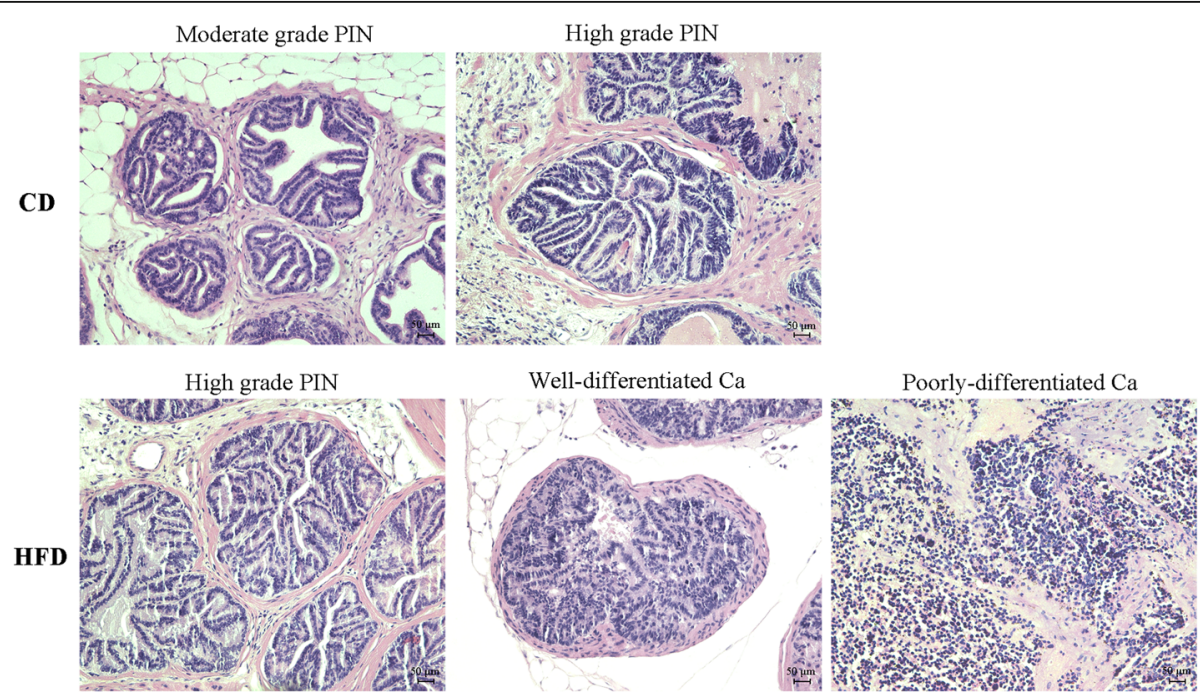

Fig. 1 Images of histopathological diagnosis of HFD and CD mice prostate. The bar represents $50 \mu \mathrm{m}$ 


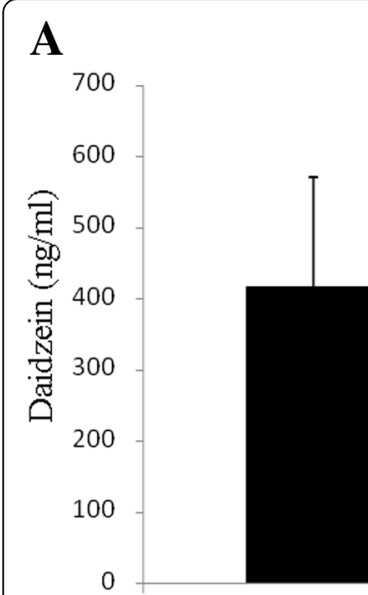

HFD

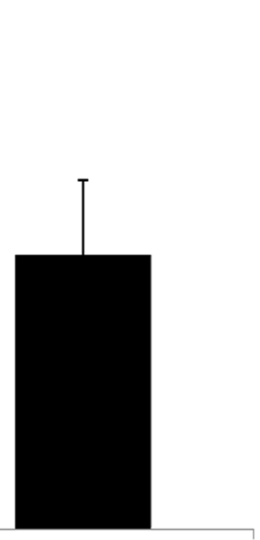

$\mathrm{CD}$

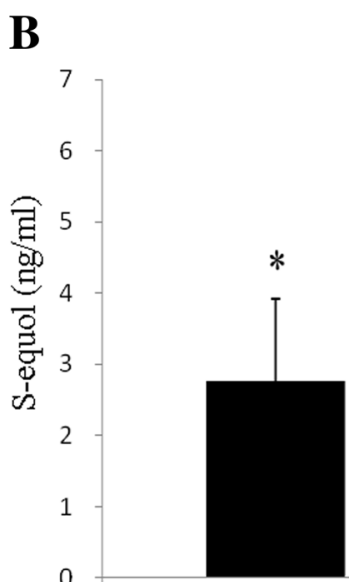

HFD

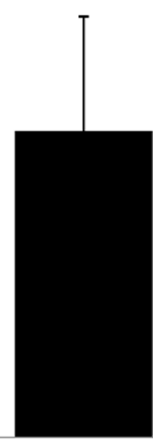

$\mathrm{CD}$

Fig. 2 Serum concentrations of daidzein $\mathbf{a}$ and S-equol $\mathbf{b}$ in HFD and CD mice. Data were expressed as means \pm SD. ${ }^{*}$ indicates $p<0.05$

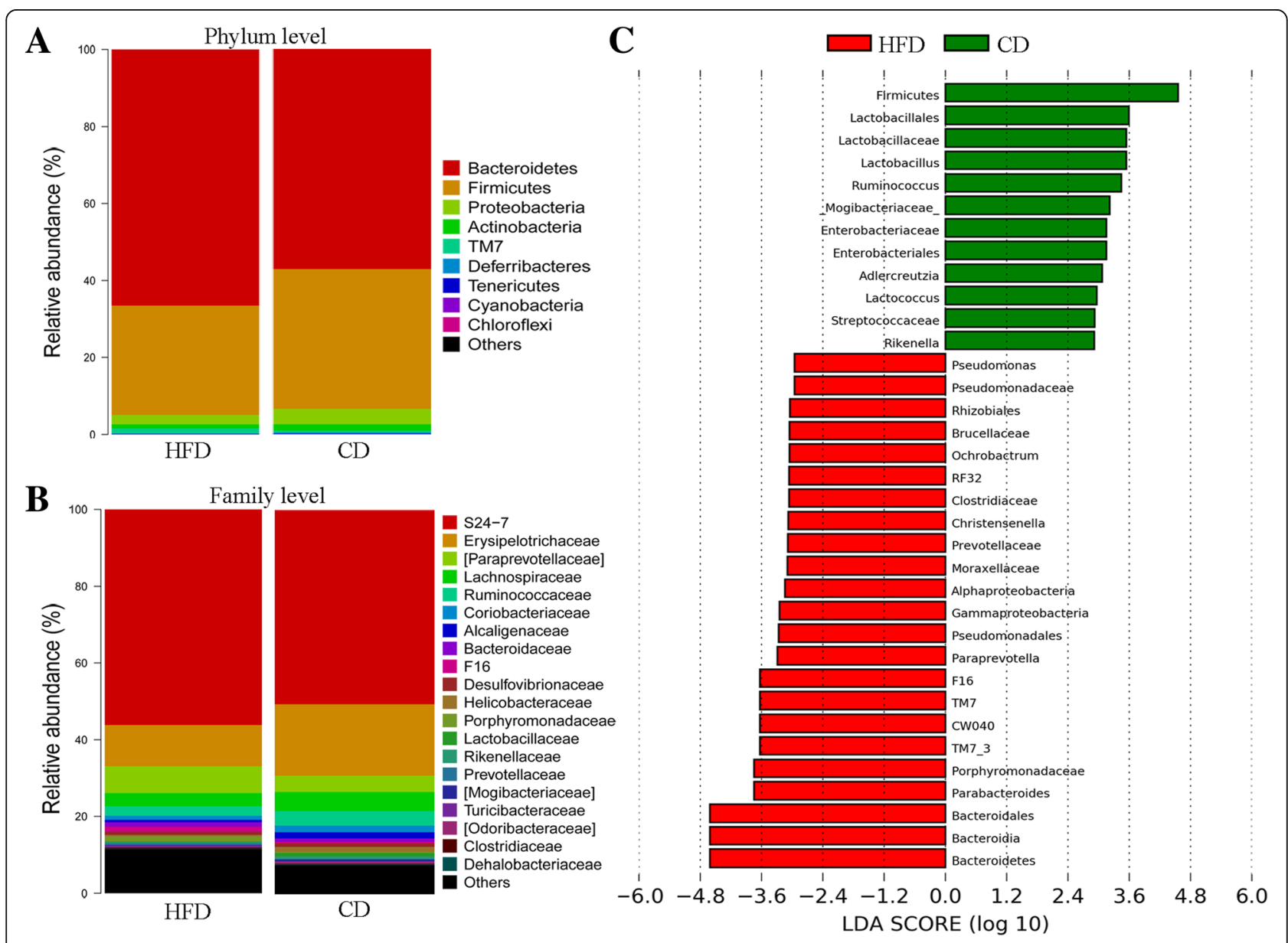

Fig. 3 Differentiated gut microbiome between HFD and CD mice. The average relative abundance of bacterial lineages of gut microbiota within HFD and CD group at the phylum $\mathbf{a}$ and family $\mathbf{b}$ level, and the key microbial phylotypes between the two groups $\mathbf{c}$ 
( $0.07 \%$ vs. $0.09 \%)$. The key differentiated microbial phylotypes in response to HFD intervention were identified with LefSe analysis, among which 21 phylotypes were increased in abundance in HFD group, and 11 were decreased in HFD group, including genus Adlercreutzia, Ruminococcus, Lactobacillus, Rikenella, Lactococcus, etc. (Fig. 3c). The detailed information was illustrated in Table 2. We also performed correlation analysis between differentiated microbial genus and the equol concentration. Significant correlations were found between equol and Adlercreutzia $(\mathrm{r}=0.699, p=0.011)$, Ruminococcus ( $\mathrm{r}=0.74, p=0.006)$, and Rikenella $(\mathrm{r}=0.582, p=0.047)$.

\section{Conclusion}

Both daidzein and its secondary metabolite equol have estrogenic properties that may contribute to protection against hormone-dependent diseases including PCa. Equol is more estrogenic than daidzein, $\mathrm{Lu}$ et al. reported that S-equol could inhibit the growth of LnCaP, DU145 and PC3 human prostate cancer cell lines via upregulating the Forkhead box O3 (FOXO3a) expression, a transcription factor with tumor suppressor functions in PCa. Also, S-equol inhibited the growth of PC3 xenograft tumors in $\mathrm{BALB} / \mathrm{c}$ nude mice [15]. In another study led by Itsumi et al., equol was proved to be able to inhibit prostate tumor growth through degradating androgen receptor by S-phase kinase-associated protein 2 [16]. Equol exists as two distinct isomers, $\mathrm{R}-(+)$ equol and $\mathrm{S}-(-)$ equol, and the latter is the natural diastereoisomer produced by bacteria in the intestine of humans and rats. Noticeably, daidzein can also be metabolized into O-desmethylangolensin (O-DMA). Though O-DMA producer phenotype is more common than equol among the population, it is much less bioactive [17]. By far, several equol-producing bacteria have been isolated from human or animal intestines, including slackia sp. strain NATTS, TM-40, Asaccharobacter celatus, Adlercreutzia equolifaciens [18-20]. In our study, dietary fat intake significantly altered the mice's gut microbiota composition, lowered the serum S-equol concentration, and promoted the prostate carcinogenesis.

Previous human and animal studies have reported the facilitative role of HFD in prostate carcinogenesis. HFD can induce prostate tumor growth through a large suite of chemical signaling pathways, such as the activation of IL6/pSTAT3 or MCP-1/CCR2 signalings, or through the inhibition of tumor suppressor gene PTEN [21-23]. In this study, HFD impaired the ability of gut microbiota to metabolize daidzein to $\mathrm{S}$-equol. The relative abundance of genus Adlercreutzia decreased below one-third in HFD mice. Adlercreutzia equolifaciens has been proved to be an equol-producing bacterium that was isolated from human feces by Maruo, et al. [24]. A positive correlation between genus Adlercreutzia and S-equol concentration was detected in this study, indicating that
Table 2 LefSe analysis of phylotypes with biologically significant differential abundance

\begin{tabular}{|c|c|c|c|}
\hline \multirow{2}{*}{$\begin{array}{l}\text { Differential phylotypes } \\
\text { by LefSe }\end{array}$} & \multicolumn{2}{|c|}{ Relative abundance (\%) } & \multirow{2}{*}{$\begin{array}{l}\text { Ratio } \\
\text { HFD to } \\
\text { CD }\end{array}$} \\
\hline & $\overline{\mathrm{HFD}}$ & $C D$ & \\
\hline \multicolumn{4}{|l|}{ Class } \\
\hline Bacteroidia & 66.527 & 57.100 & 1.17 \\
\hline TM7-3 & 1.331 & 0.452 & 2.94 \\
\hline Gammaproteobacteria & 0.318 & 0.012 & 26.5 \\
\hline Alphaproteobacteria & 0.316 & 0.085 & 3.72 \\
\hline \multicolumn{4}{|l|}{ Order } \\
\hline Bacteroidales & 66.527 & 57.100 & 1.17 \\
\hline CW040 & 1.331 & 0.452 & 2.94 \\
\hline Pseudomonadales & 0.318 & 0 & - \\
\hline RF32 & 0.280 & 0.083 & 3.37 \\
\hline Lactobacillales & 0.151 & 0.954 & 0.16 \\
\hline Rhizobiales & 0.022 & 1.97E-05 & 1116.75 \\
\hline Enterobacteriales & 0 & 0.012 & - \\
\hline \multicolumn{4}{|l|}{ Family } \\
\hline Porphyromonadaceae & 1.357 & 0.279 & 4.86 \\
\hline F16 & 1.331 & 0.452 & 2.94 \\
\hline Prevotellaceae & 0.450 & 0.215 & 2.09 \\
\hline Clostridiaceae & 0.306 & 0.130 & 2.35 \\
\hline Moraxellaceae & 0.180 & 0 & - \\
\hline Lactobacillaceae & 0.149 & 0.858 & 0.17 \\
\hline Pseudomonadaceae & 0.138 & 0 & - \\
\hline Mogibacteriaceae & 0.131 & 0.432 & 0.30 \\
\hline Brucellaceae & 0.022 & 1.97E-05 & 1116.75 \\
\hline Streptococcaceae & 1.97E-05 & 0.029 & 0.001 \\
\hline Enterobacteriaceae & 0 & 0.012 & - \\
\hline \multicolumn{4}{|l|}{ Genus } \\
\hline Parabacteroides & 1.357 & 0.279 & 4.86 \\
\hline Paraprevotella & 0.416 & 0.034 & 12.24 \\
\hline Ruminococcus & 0.310 & 0.878 & 0.35 \\
\hline Lactobacillus & 0.149 & 0.858 & 0.17 \\
\hline Pseudomonas & 0.138 & 0 & - \\
\hline Adlercreutzia & 0.080 & 0.278 & 0.29 \\
\hline Christensenella & 0.053 & $3.94 \mathrm{E}-05$ & 1345.18 \\
\hline Ochrobactrum & 0.022 & 1.97E-05 & 1116.75 \\
\hline Rikenella & 0 & 0.085 & - \\
\hline Lactococcus & 0 & 0.029 & - \\
\hline
\end{tabular}

the decreased Adlercreutzia may contribute to the lower level of equol concentration.

Several differentiated microbial floras identified in HFD mice have been proved to be associated with PCa. For example, genus Lactobacillus was decreased in HFD mice. Some strains in Lactobacillus are capable of 
activating NK activity of peripheral blood mononuclear cells (PBMCs) against prostate cancer cells [25]. In an PC-3 xenograft rodent model, genus Lactobacillus was found to be elevated in mice with suppressed tumor growth [26]. The genus Ochrobactrum was intensely increased in HFD mice. It was also found to be overexpressed in expressed prostatic secretions of PCa patients [27]. We also observed an increased abundance of phylum Bacteroidetes and decreased Firmicutes in HFD mice. Whether the ratio of Bacteroidetes/Firmicutes is associated with obesity remains controversial, for example, Turnbaugh et al. reported decreased while Schwiertz et al. reported increased Bacteroidetes/Firmicutes ratio in obese humans $[28,29]$. Golombos et al. compared the gut microbiome between PCa patients and patients with benign prostatic hypertrophy, and found that Bacteriodes massiliensis, which belongs to Bacteroidetes was significantly increased in cancer patients [30].

No significant differences were observed in the daidzein concentration, indicating that HFD did not significantly influence the daidzein absorption. Previous studies proposed that some strains in clostridia may participate in isoflavone degradation and metabolism [31]. Correspondingly, no significant differences were observed in the relative abundance of Clostridia between HFD and CD groups (17.04\% vs. $16.64 \%)$.

In summary, the present study suggested that dietary high fat intake may promote prostate carcinogenesis via adversely affecting the gut microbiota and microbiota-mediated equol metabolism. Further functional validations are needed to ascertain the exact roles of those differentiated microbial floras, and their potentials to be used as new targets for PCa prevention.

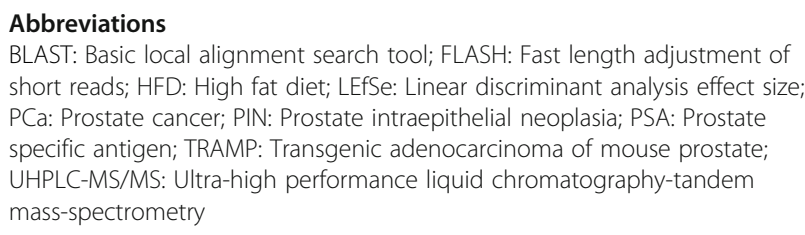

\section{Acknowledgments}

We thank Department of Pathology, Huashan Hospital for their assistance in histopathological diagnosis of mice prostate.

\section{Funding}

This study was supported by National Natural Science Foundation of China (No. 81872102).

\section{Availability of data and materials}

The sequencing datasets generated during the current study are available in the NCBI PDA repository with an accession number of PRJNA509061.

\section{Authors' contributions}

$J H W$ conceptualized the project. LYF designed the study, analyzed the data and wrote the paper. LYF and WXB performed the experiments. All authors have read and approved the manuscript.
Ethics approval and consent to participate

Animals were handled with IACUC approval by the Fudan University (Grant No. 20171674 A641).

\section{Consent for publication}

Not applicable.

\section{Competing interests}

The authors declare that they have no competing interests.

\section{Publisher's Note}

Springer Nature remains neutral with regard to jurisdictional claims in published maps and institutional affiliations.

Received: 9 January 2019 Accepted: 29 March 2019

Published online: 11 April 2019

\section{References}

1. Lindsey AT, Freddie B, Rebecca LS, Jacques F, Joannie LT, Ahmedin J. Global Cancer statistics, 2012. CA Cancer J Clin. 2015;65:87-108.

2. Applegate CC, Rowles JL, Ranard KM, Jeon S, Erdman JW. Soy consumption and the risk of prostate Cancer: an updated systematic review and metaanalysis. Nutrients. 2018;10:E40.

3. Patel VH. Nutrition and prostate cancer: an overview. Expert Rev Anticancer Ther. 2014;14:1295-304.

4. Mahmoud AM, Yang W, Bosland MC. Soy isoflavones and prostate cancer: a review of molecular mechanisms. J Steroid Biochem Mol Biol. 2014;140:116-32.

5. van Die MD, Bone KM, Williams SG, Pirotta MV. Soy and soy isoflavones in prostate cancer: a systematic review and meta-analysis of randomized controlled trials. BJU Int. 2014;113:E119-30.

6. Rabiau N, Kossaï M, Braud M, Chalabi N, Satih S, Bignon YJ, Bernard-Gallon DJ. Genistein and daidzein act on a panel of genes implicated in cell cycle and angiogenesis by polymerase chain reaction arrays in human prostate cancer cell lines. Cancer Epidemiol. 2010;34:200-6.

7. Kurahashi N, Iwasaki M, Inoue M, Sasazuki S, Tsugane S. Plasma isoflavones and subsequent risk of prostate cancer in a nested case-control study: the Japan public health center. J Clin Oncol. 2008;26:5923-9.

8. Setchell KD, Clerici C. Equol. History, chemistry, and formation. J Nutr. 2010; 140:1355S-62S.

9. Motoi T, Kazuhiro H, Kikuji I, Kazuki S. Effects of human intestinal Flora on plasma and Caecal Isoflavones, and effects of Isoflavones on the composition and metabolism of Flora in human Flora-associated (HFA) mice. Microb Ecol Health Dis. 2004;16:18-22.

10. Caporaso JG, Kuczynski J, Stombaugh J, Bittinger K, Bushman FD, Costello EK, Fierer N, Pena AG, Goodrich JK, Gordon Jl, et al. QIIME allows analysis of high-throughput community sequencing data. Nat Methods. 2010;7:335-6.

11. Magoc T, Salzberg SL. FLASH: fast length adjustment of short reads to improve genome assemblies. Bioinformatics. 2011;27:2957-63.

12. Edgar RC. Search and clustering orders of magnitude faster than BLAST. Bioinformatics. 2010;26:2460-1.

13. Segata N, lzard J, Waldron L, Gevers D, Miropolsky L, Garrett WS, Huttenhower C. Metagenomic biomarker discovery and explanation. Genome Biol. 2011;12:R60.

14. Shannon CE. The mathematical theory of communication. 1963. MD Comput. 1997;14:306-17.

15. Lu Z, Zhou R, Kong Y, Wang J, Xia W, Guo J, Liu J, Sun H, Liu K, Yang J, et al. S-equol, a secondary metabolite of natural anticancer Isoflavone Daidzein, inhibits prostate Cancer growth in vitro and in vivo, though activating the Akt/FOXO3a pathway. Curr Cancer Drug Targets. 2016;16:455-65.

16. Itsumi M, Shiota M, Takeuchi A, Kashiwagi E, Inokuchi J, Tatsugami K, Kajioka S, Uchiumi T, Naito S, Eto M, Yokomizo A. Equol inhibits prostate cancer growth through degradation of androgen receptor by S-phase kinaseassociated protein 2. Cancer Sci. 2016;107:1022-8.

17. Gaya P, Medina M, Sánchez-Jiménez A, Landete JM. Phytoestrogen Metabolism by Adult Human Gut Microbiota. Molecules. 2016;21:E1034.

18. Akaza H. Prostate cancer chemoprevention by soy isoflavones: role of intestinal bacteria as the "second human genome". Cancer Sci. 2012;103:969-75.

19. Tamura M, Tsushida T, Shinohara K. Isolation of an isoflavone-metabolizing, clostridium-like bacterium, strain TM-40, from human faeces. Anaerobe. 2007;13:32-5. 
20. Vazquez L, Guadamuro L, Giganto F, Mayo B, Florez AB. Development and use of a real-time quantitative PCR method for detecting and quantifying Equol-producing Bacteria in human Faecal samples and slurry cultures. Front Microbiol. 2017:8:1155.

21. Hayashi T, Fujita K, Nojima S, Hayashi Y, Nakano K, Ishizuya Y, Wang C, Yamamoto Y, Kinouchi T, Matsuzaki K, et al. High-fat diet-induced inflammation accelerates prostate Cancer growth via IL6 signaling. Clin Cancer Res. 2018;24:4309-18.

22. Huang M, Narita S, Numakura K, Tsuruta $H$, Saito M, Inoue T, Horikawa Y, Tsuchiya N, Habuchi T. A high-fat diet enhances proliferation of prostate cancer cells and activates MCP-1/CCR2 signaling. Prostate. 2012;72:1779-88.

23. Kwon OJ, Zhang B, Zhang L, Xin L. High fat diet promotes prostatic basalto-luminal differentiation and accelerates initiation of prostate epithelial hyperplasia originated from basal cells. Stem Cell Res. 2016;16:682-91.

24. Maruo T, Sakamoto M, Ito C, Toda T, Benno Y. Adlercreutzia equolifaciens gen. Nov., sp. nov., an equol-producing bacterium isolated from human faeces, and emended description of the genus Eggerthella. Int J Syst Evol Microbiol. 2008;58:1221-7.

25. Horinaka M, Yoshida T, Kishi A, Akatani K, Yasuda T, Kouhara J, Wakada M, Sakai T. Lactobacillus strains induce TRAIL production and facilitate natural killer activity against cancer cells. FEBS Lett. 2010;584:577-82.

26. Ni X, Yu H, Wang S, Zhang C, Shen S. Astaxanthin inhibits PC-3 xenograft prostate tumor growth in nude mice. Mar Drugs. 2017;15:E66.

27. Yu H, Meng H, Zhou F, Ni X, Shen S, Das UN. Urinary microbiota in patients with prostate cancer and benign prostatic hyperplasia. Arch Med Sci. 2015; 11:385-94.

28. Turnbaugh PJ, Ley RE, Mahowald MA, Magrini V, Mardis ER, Gordon Jl. An obesity-associated gut microbiome with increased capacity for energy harvest. Nature. 2006;444:1027-31.

29. Schwiertz A, Taras D, Schafer K, Beijer S, Bos NA, Donus C, Hardt PD. Microbiota and SCFA in lean and overweight healthy subjects. Obesity (Silver Spring). 2010;18:190-5.

30. Golombos DM, Ayangbesan A, O'Malley P, Lewicki P, Barlow L, Barbieri CE, Chan C, DuLong C, Abu-Ali G, Huttenhower C, Scherr DS. The role of gut microbiome in the pathogenesis of prostate Cancer: a prospective, pilot study. Urology. 2018;111:122-8.

31. Winter J, Moore LH, Dowell VR Jr, Bokkenheuser VD. C-ring cleavage of flavonoids by human intestinal bacteria. Appl Environ Microbiol. 1989;55: $1203-8$

Ready to submit your research? Choose BMC and benefit from:

- fast, convenient online submission

- thorough peer review by experienced researchers in your field

- rapid publication on acceptance

- support for research data, including large and complex data types

- gold Open Access which fosters wider collaboration and increased citations

- maximum visibility for your research: over $100 \mathrm{M}$ website views per year

At $\mathrm{BMC}$, research is always in progress.

Learn more biomedcentral.com/submissions 